\title{
Assessment of a gravity-based approach to constructing future spatial population scenarios
}

\author{
Bryan Jones
}

Published online: 21 January 2014

(C) The Author(s) 2014. This article is published with open access at Springerlink.com

\begin{abstract}
Spatially explicit projections of global population are of growing importance in scenario-based assessment of anthropogenic climate change and climate related vulnerability. However, to date there are very few spatially explicit projections of the future distribution of global population, and methods for producing such projections are in their infancy. One of the most sophisticated methods currently available, developed as part of the Greenhouse Gas Initiative at the IIASA (Grübler et al. in Technol Forecast Soc Change 74(7):980-1029, 2007), uses the gravity-based population potential model to produce scenario dependent projections. Population potential is widely used as a descriptive tool and in models of spatial allocation. While it is attractive through its simplicity and ability to summarize complex patterns, the population potential model suffers from several well documented problems. This paper provides an assessment of population potential as a tool for constructing future spatial population scenarios, particularly within the context of the pitfalls associated with the model. Despite improvements over other existing methods, it was found that the model is capable of producing only a narrow range of spatial outcomes, is subject to border effects, is restrictive in its handling of urban and rural population dynamics, and will in most cases misallocate population loss. The potential-allocation approach to producing large-scale spatial population scenarios is promising, but several methodological modifications are necessary to address the model's shortcomings.
\end{abstract}

Keywords Spatial population · Gravity model · Population potential · Population projections 


\section{Introduction}

Changes in the size, structure, and spatial distribution of the population through various socio-economic and political mechanisms are important influences in the human-environment relationship. Along with other factors such as technological change, characteristics of the population will influence the degree to which human activities affect, and are affected by, anthropogenic climate change. Spatially explicit projections of global population are of growing importance in scenariobased assessment of, for example, the spatial distribution of land use, demand for food and water, energy usage, and emissions (Raupach et al. 2010; Rockström et al. 2009; Small 2004). Similarly, spatial population data are frequently used to assess human vulnerability to natural and man-made hazards, and increasingly, to the potential consequences of global climate change (Arnell 2004; Balk et al. 2009).

The biophysical data used in high-resolution global change models are most often organized on a regular lattice grid while demographic data are typically aggregated according to existing administrative boundaries (Balk et al. 2006). The gridding of demographic data is thus a necessary step for inclusion in most high-resolution global change models. Over the past two decades there have been significant improvements in the quality and availability of large-scale gridded population data (CIESIN 2011; Dobson et al. 2000). However, to date there are very few spatially explicit projections of the future distribution of the global population, and methods for producing such projections are in the early stages of development. Most existing spatially explicit projections are constructed using simple scaling techniques or trend extrapolation (van Vuuren et al. 2007; Hachadoorian et al. 2011). ${ }^{1}$ By definition these data reflect a future world in which the spatial population structure does not change, or changes only through continuation of the most recent subregional trend.

One of the most sophisticated methods currently available, developed as part of the Greenhouse Gas Initiative at IIASA ${ }^{2}$ (Grübler et al. 2007), uses a gravity-based spatial allocation model to produce scenario-dependent projections. More specifically, the method draws on the concept of population potential (Stewart 1942) to downscale future projections of national-level population change. These data have been used in scenario-oriented climate research based on the widely cited Intergovernmental Panel on Climate Change (IPCC) Special Report on Emissions Scenarios (SRES) (Nakicenovic et al. 2000; Riahi et al. 2007) and the more recent representative concentration pathways (RCPs) currently in development for the next IPCC assessment report (van Vuuren et al. 2011). The IIASA scenarios represent one of the only future global spatial population datasets in which spatial outcomes are not strictly limited to scaled versions of the existing population. Furthermore, the IIASA approach represents a unique application of the population potential model in which potential is used as a dynamic tool for downscaling projected future

\footnotetext{
${ }^{1}$ Two exceptions include Asadoorian (2005) and Nam and Reilly (2012), both of which rely on the correlation between a beta function derived from the national rank-size distribution of grid cells and socio-economic variables.

${ }^{2}$ International Institute for Applied Systems Analysis (IIASA), Laxenburg, Austria.
} 
population change. The population potential model, however, is subject to several well documented problems. The purpose of this paper is to provide a detailed assessment of the population potential-based approach to constructing future spatial population scenarios within the context of recognized patterns of spatial population change and the issues known to affect the population potential model.

The next section of the paper reviews the "population potential" model, including its uses, interpretation, and shortcomings. The "IIASA potential-based allocation procedure" is then introduced in the third section. The fourth section of the paper provides an assessment of population potential as a tool for constructing future spatial population scenarios, using the IIASA model as a point of reference when necessary. "Conclusions and recommendations" are presented in the fifth and final section.

\section{Population potential}

Gravity-type models in demography generally seek to simulate human behaviour in the aggregate, a function for which they are widely used. Population potential can be interpreted as a measure of the influence that the population at one point in space exerts on another point. In this context, and summed over all points within an area, population potential represents an index of the relative influence that the population within a region exerts on each point within that region:

$$
V_{i}=\sum_{j=1}^{m} \frac{P_{j}}{D_{i j}}
$$

where $P_{j}$ is the population at each point $j$, and $D_{i j}$ is the distance between each point $j$ and point $i$ for which potential is calculated. ${ }^{3}$

Population potential can be considered an indicator of the potential for interaction between the population at a given point in space and all other populations (Rich 1980). Naturally this potential will be higher at points existing in closer proximity to large populations, thus potential is also an indicator of the relative proximity of the existing population to each point within an area (Warntz and Wolff 1971). Similarly, and for practical purposes, population potential is often considered a proxy for accessibility (Rich 1980), indicating the relative ease with which human populations may be accessed from a given point. Extending this line of reasoning, if access to population is considered a proxy for access to the

\footnotetext{
3 The classic formulation of potential, as derived from Newton's laws of gravitation, uses a distance exponent of one (Stewart and Warntz 1958). There has been considerable debate over the appropriate distance exponent (see Pooler 1987; Rich 1980); some arguing for a more general version of population potential:

$V_{i}=\sum_{j=1}^{m} \frac{P_{j}}{D_{i j}^{b}}$

where the distance exponent (b) may be derived from observed data regarding interaction (Yeates 1974). Potential is measured in people per unit of distance, a metric that is similar, but not identical, to population density (O'Kelly and Horner 2003).
} 
consumer marketplace, employment opportunities, and urban amenities, then potential can also be considered a relative measure of attractiveness.

In general, people choose to reside in places they deem to be attractive. While the definition of attractiveness will vary for individuals, research suggest that in the aggregate locational choice can be tied to factors such as economic opportunity, transportation infrastructure, proximity to family, the presence of social amenities, and intangibles such as place attachment (Clark and Davies 2002; Gustafson 2001; Kim et al. 2005). Additionally, populations are constrained in their choices by economic and geopolitical factors. Within this context, the spatial distribution of the population reflects the aggregate perception of the relative attractiveness of places subject to certain constraints. Correspondingly, changes in spatial distributions over time reflect changing perceptions. Empirically, the tendency of human populations to gravitate towards larger urban agglomerations, reflected in the steady rise in global urbanization rates, supports the notion that the presence of population is indicative of relative attractiveness, reflected through residential choice. However, within the population potential framework it is difficult to tease out the degree to which certain factors, for instance job opportunities versus social amenities, are responsible for attractiveness, a shortcoming of the model that merits future consideration.

As an aid in modelling spatial patterns and processes, population potential is a versatile tool used in a wide variety of recent applications. Improvements in spatial modelling software and GIS technology are causing an influx of potential-based accessibility modelling related to market access and economic development (Vickerman et al. 2010), labour productivity (Polyzos and Arambatzis 2006), planning (Geertman and Ritsema Van Eck 1995), and recreation (Weber and Sultana 2012). As an indicator for proximity, potential is often used to indicate centrality/isolation in research assessing, for example, health care access (Haynes et al. 2003; Rosero-Bixby 2004), social well-being (Middleton et al. 2003), distance-to-work (Shuttlesworth and Gould 2010), and access to services (Haugen et al. 2012). Spatial land-use land-cover change and ecosystem impact research often considers population potential as an explanatory variable, particularly in relation to urban land cover and threats to the natural environment (Braimoh and Onishi 2007; Verburg et al. 2004) The potential model has also been used in smart interpolation applications to estimate the gridded distribution of human population (Deichmann and Eklundh 1991; Sweitzer and Langaas 1995; Wang and Guldmann 1996).

Despite its wide use, the population potential model has been shown to exhibit several potentially problematic features, the most well documented of which is the 'self-potential problem'. In the classic Stewart formulation (Eq. 1) the contribution of the population at each point $j$ is weighted by the inverse of distance to point $i$, which at point $i$ is zero. This singularity leads to the exclusion of any contribution from the population at point $i$ to the potential of point $i$ which, within the context of attractiveness, is the equivalent of assuming that the characteristics of a particular point in space do not affect the perceived attractiveness of that point relative to others. From a mechanical perspective, lack of a self-potential term reinforces a dynamic tendency towards homogeneity in the potential surface, as potential at each 
point in space is a distance-weighted average of the population at surrounding points and thus acts as a smoothing agent (Sheppard 1979). A number of proposed solutions to the self-potential problem exist in the literature, including alternative distance-decay functions that eliminate the singularity. Pooler (1987) and Frost and Spence (1995) provide a more detailed review of both the self-potential problem and alternative solutions.

A second problem with the potential model is its vulnerability to border effects. Craig (1987) shows that population potential generally declines in proximity to a coastline or some other boundary, a result of the larger average distance from peripheral points (relative to centrally located points) to all other points within an area. In certain accessibility-type models Craig argues that the 'positional effect' provides an accurate representation of spatial systems, as peripheral points are often less accessible than central points. However, if potential is considered a measure of density and/or attractiveness, then the positional effect should be removed, as there is no reason to believe, for example, that a coastal location is inherently less attractive than a central inland location.

In addition to these problematic features it has been argued that strict adherence to the physical potential analogy is not necessary or appropriate in the social sciences (Pooler 1987; Rich 1980), leading many to consider distance exponents other than unity or alternative distance response functions (Ingram 1970; Weibull 1976). It is likely that the appropriate distance-response function in any model will vary according to regional characteristics of the population as well as the aggregation of the input units and the bandwidth over which potential is calculated. ${ }^{4}$ Sheppard (1979) and Pooler (1987) both suggest that rigid distance-response functions can lead to misleading results.

Despite these shortcomings, if it is assumed that humans are more likely to settle in places that are more accessible and/or attractive, then it stands to reason that the population potential model could provide a fair approximation of the distribution of projected changes in the future population.

\section{The IIASA potential-allocation procedure}

The IIASA downscaling algorithm consists of four basic steps which are iterated at each time interval: (1) define grid cells within a particular country as urban or rural (2) calculate a population potential for each grid cell (3) allocate projected national urban population change to urban grid cells proportionally according to their respective population potentials, and (4) allocate projected national rural population change to rural grid cells proportionally according to existing population.

Starting from a gridded distribution of the population, grid cells are selected and classified as urban on the basis of existing urban extents, population density, and the

\footnotetext{
${ }^{4}$ In certain models potential is calculated at each point as a function of only those points falling within a certain distance (Rich 1980).
} 
spatial distribution of night-time light intensity. ${ }^{5}$ Within each country, cells are selected and classified as urban until the population within those cells matches the national-level urban population total. The remaining cells are then classified as rural.

At the beginning of each time interval a population potential is calculated for each grid cell as the sum of two terms: the contribution from other nearby urban populations, and the contribution from other nearby rural populations. Potential for each cell is calculated as:

$$
V_{i}=\sum_{j=1}^{m} \frac{P_{j, u}}{D_{i j}^{2}}+\sum_{k=1}^{n} \frac{P_{k, r}}{D_{i k}^{2}}
$$

where $v_{i}$ is potential of cell $i, P$ is population within a grid cell, $D$ is geographic distance between two grid cells, $j$ is an index of the $m$ other cells within the urban 'window' around cell $i$, and $k$ is an index of the $n$ other cells within the rural 'window' used in the calculation of potential. The urban window $m$ comprises all cells containing urban population that fall within a 25-cell radius, and the rural window $n$ consists of all cells containing rural population within a 5-cell radius. ${ }^{6}$ Potential is calculated for all grid cells within a country, with no contributions to potential from grid cells outside national borders.

Within each country, at each time step, projected change in the urban population is allocated across urban cells proportionally according to potential. A maximumdensity constraint of roughly $35-45 \mathrm{k} / \mathrm{km}^{2}$ is applied to prevent very large densities. Projected rural population change is allocated across all rural cells proportionally according to the existing distribution of the population. This alternative approach in distributing rural change is attributed to a 'lack of deeper theoretical understanding of the drivers of regionally differentiated growth in rural areas' (Grübler et al. 2007). Once projected national-level changes in the urban and rural components of the population are distributed, the process begins anew for the subsequent time step.

\section{Assessment}

To assess the potential model as a tool for constructing spatial population scenarios, the IIASA procedure is applied to several hypothetical and real-world population distributions. Simulations using a hypothetical population existing in one-dimensional space, the simplest array of grid cells chosen for ease of analysis, are considered first. From these one-dimensional simulations broad patterns and trends are identified and analysed in more complex two-dimensional scenarios. The advantage of these hypothetical simulations is control over the variables that affect

\footnotetext{
5 In their application of the model IIASA used the 1990 Gridded Population of the World (GPW) as the base-year distribution, urban extents from the Earth Science Information Network (ESRI) Digital Chart of the World (DCW), and night-time light intensity from the US National Oceanic and Atmospheric Administration (NOAA) Defense Meteorological Satellite Program's (DMSP) Operational Linescan System.

6 The urban and rural windows have radii of $3.125^{\circ}$ and $0.625^{\circ}$, respectively, which equate to roughly 350 and $70 \mathrm{~km}$ at the equator and 265 and $50 \mathrm{~km}$ at the mid-latitudes.
} 
spatial outcomes produced by the potential-allocation procedure, including the baseyear distribution; geography (i.e., the size of the study area); the urban/rural classification (both the geographic distribution of urban/rural cells and the portion of the base-year population classified as urban/rural, and the rate of population change. Conclusions are drawn from the hypothetical simulations which are then assessed using gridded distributions of the observed and projected United States population.

Through the course of this work it was advantageous to first apply the model to hypothetical populations defined entirely as urban, isolate the forces driving the observed spatial outcomes, and then consider more complicated urban/rural and real-world systems. This assessment references both urban-only and urban/rural scenarios. In most cases, understanding and interpreting the urban-only results eases the interpretation of the urban-rural results. Finally, in this assessment of the model the full potential-allocation procedure is applied to the rural population as opposed to using a proportional scaling procedure. This decision reflects an intention to model both urban and rural population dynamics.

Results and analysis

The potential-allocation methodology is deterministic in nature. Thus the base-year definitions and model specifications that affect the calculation of potential ultimately determine spatial outcomes. A detailed assessment of the potentialbased downscaling procedure was carried out and five key characteristics of the method that affect spatial population outcomes were identified: (1) the distanceresponse function and bandwidth limit the range of possible spatial outcomes; (2) the model is subject to border effects; (3) the urban/rural classification and allocation algorithm can lead to unrealistic spatial patterns on the urban/rural border and affect projected patterns of urbanization; (4) population loss is misallocated; and (5) population is allocated to areas unsuitable for human development. These characteristics can all be linked to specific mechanisms and definitions within the algorithm. Each of these points is now discussed in turn.

\section{Limited patterns of spatial change}

The potential-allocation procedure is only capable of producing a narrow range of spatial patterns of population change. In most realistic scenarios the model acts as a spatial smoothing agent which leads to a pattern of dispersion over time. Only in regions exhibiting a relatively uniform distribution of the base-year population will the model project a pattern of consolidation. Figure $1 \mathrm{a}$ and $\mathrm{b}$ illustrate this trend in $\mathrm{a}$ set of controlled urban-only one-dimensional scenarios. Figure 1a illustrates a baseyear population distributed normally across the test region (indicative of a monocentric distribution) and a 100-year spatial outcome indicative of population dispersion. Figure $1 \mathrm{~b}$ considers a randomly distributed base-year population and demonstrates the model's tendency to smooth polycentric populations. In Fig. 2a and $b$ this trend is illustrated using the Atlanta MSA and the IIASA 100-year spatial 

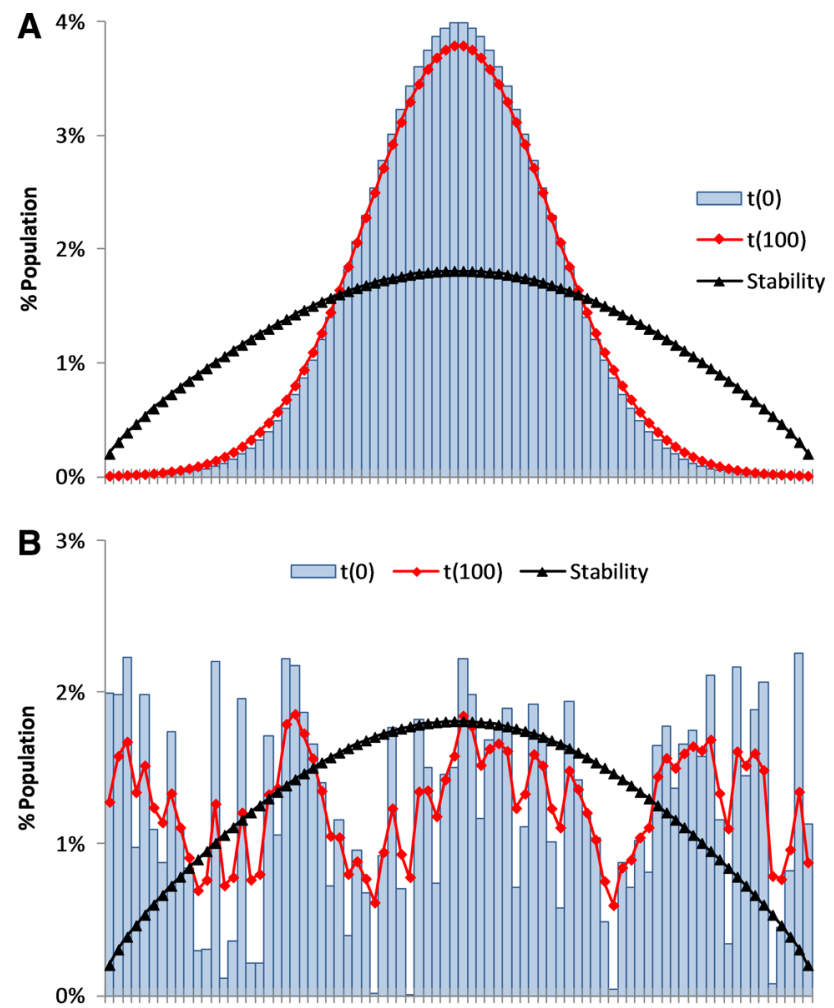

Fig. 1 Population distribution in the base-year, after 100 years, and at stability; a normal distribution and $\mathbf{b}$ random distribution, $\mathrm{r}=0.01$

projection consistent with the A2 scenario $^{7}$ from the widely used SRES storylines (see Nakicenovic et al. 2000).

There are three characteristics of the model that contribute to this phenomenon: the fixed distance-response function; the large bandwidth associated with the population potential window; and lack of a self-potential term. In the case of the first two characteristics, direct parallels to point-pattern analysis or kernel-density estimation are appropriate. When, for example, constructing a map of values over a continuous surface for a variable measured at specific points in space, it is common practice to 'fill-in' the space where no measurements were taken by calculating a distance-weighted average at every point within the area (Bailey and Gatrell 1995). The form of the final surface is largely a function of two factors, the bandwidth and distance-decay function chosen to calculate the average at each point. Smaller bandwidths and steeper decay functions lead to a noisier surface, while larger bandwidths and shallower functions lead to a smoother surface. Whereas potential can be considered a distance-weighted measure of population density (Craig 1987), it can be inferred that the same two factors will govern the level of dispersion or

\footnotetext{
7 The population component of the A2 storyline represents a differentiated world in which local emphasis on family and community life slows the decline in fertility rates, leading to more rapid population growth.
} 
A Observed Population Density Atlanta MSA, 1990

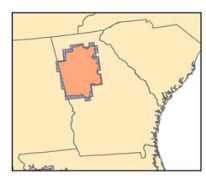

Legend Pop Density $\left(\mathrm{km}^{2}\right)$

$\square$
$\square$

प $20-50$

$50-100$

$100-250$

$250-500$

$500-1,000$

$>1,000$
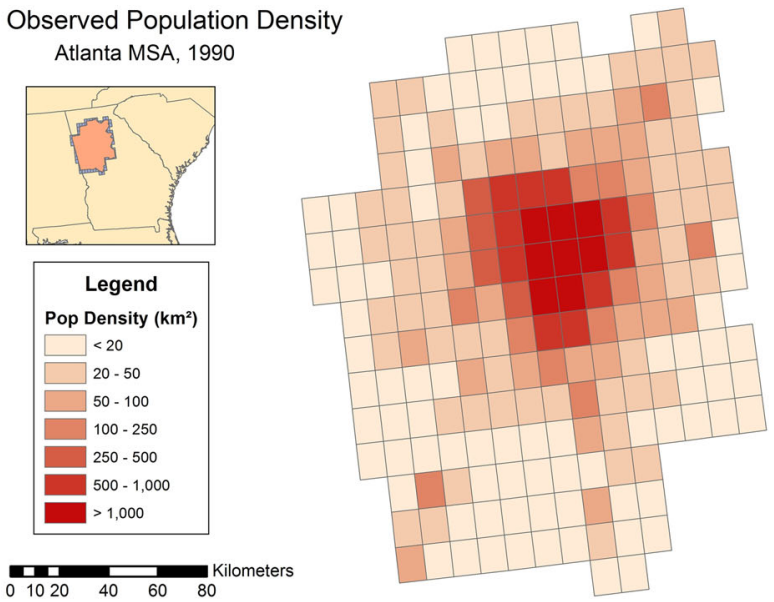

B

Observed Population Density

Atlanta MSA, 1990

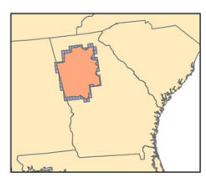

Legend

Pop Density $\left(\mathrm{km}^{2}\right)$

$\square<20$

$20-50$

$50-100$

$100-250$

$500-1,000$

$1,000+$
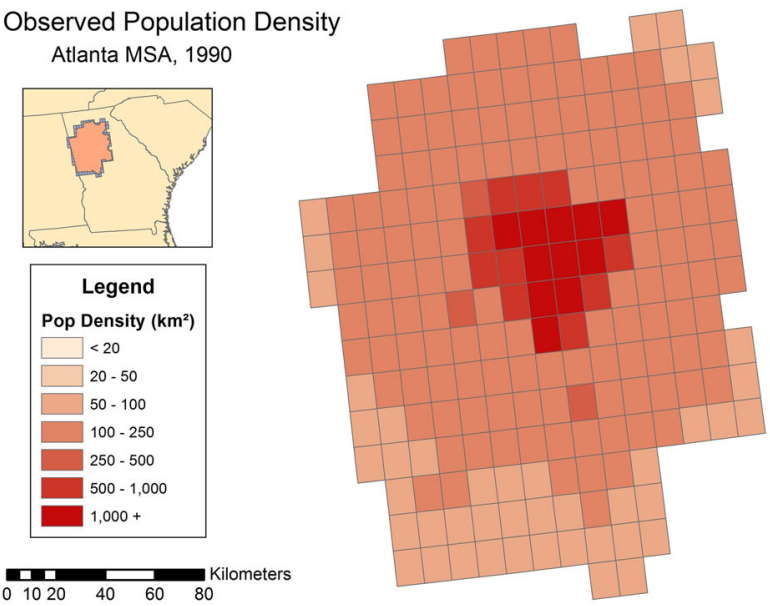

Fig. 2 a Observed and $\mathbf{b}$ predicted population density in the Atlanta MSA; IIASA A2 scenario

concentration in spatial population outcomes. The distance-decay function is used to weight the contribution of nearby populations to potential, while bandwidth is the direct correlate of window size.

The IIASA spatial downscaling procedure is based on population potential calculated as prescribed in Eq. 2. The method uses a fixed distance-decay exponent equal to two, which severely limits the types of spatial patterns that the model is able to produce. Within the context of population potential, the distance-response function is an indicator of the degree to which distance impedes accessibility. A fixed distance-decay function suggests that the distance/accessibility relationship does not vary over space: the model enforces a similar spatial pattern across all regions. From the results in Figs. 1 and 2 it can be hypothesized that this pattern will typically be one of dispersion. 
The IIASA potential-allocation procedure uses fixed windows of $3.125^{\circ}$ and $0.625^{\circ}$ for urban and rural populations, respectively. As was noted above, larger windows lead to smoother (more dispersed) population outcomes. To demonstrate, consider Figs. 3 and 4 which illustrate the urban and rural windows centred on Denver, Colorado as well as the potential gradients that result from applying these windows in the calculation of potential. Calculated over the urban window (Fig. 3) the population in Denver is influential (contributes to potential) in places as far away as Scottsbluff, Nebraska. Over the rural window (Fig. 4), however, this influence would extend only as far as Longmont, Colorado. Using the larger urban window the potential gradient extending outward from Denver declines in shallower fashion leading to a more dispersed allocation of population change. Because the bulk of the world's population growth is projected to be urban, the urban window is far more important in a potential-allocation procedure that differentiates between urban and rural components.

The self-potential problem, described in the previous section, ensures that the IIASA method will impose a pattern of dispersion on almost all regional populations; the lone exception is a population that is distributed uniformly, as discussed below. Without a self-potential term the calculation of potential for each cell $i$ is essentially a distance-weighted measure of the population in other nearby cells. Thus, those cells most likely to have large potentials are those located near densely populated cells, but they need not be densely populated themselves. Applied
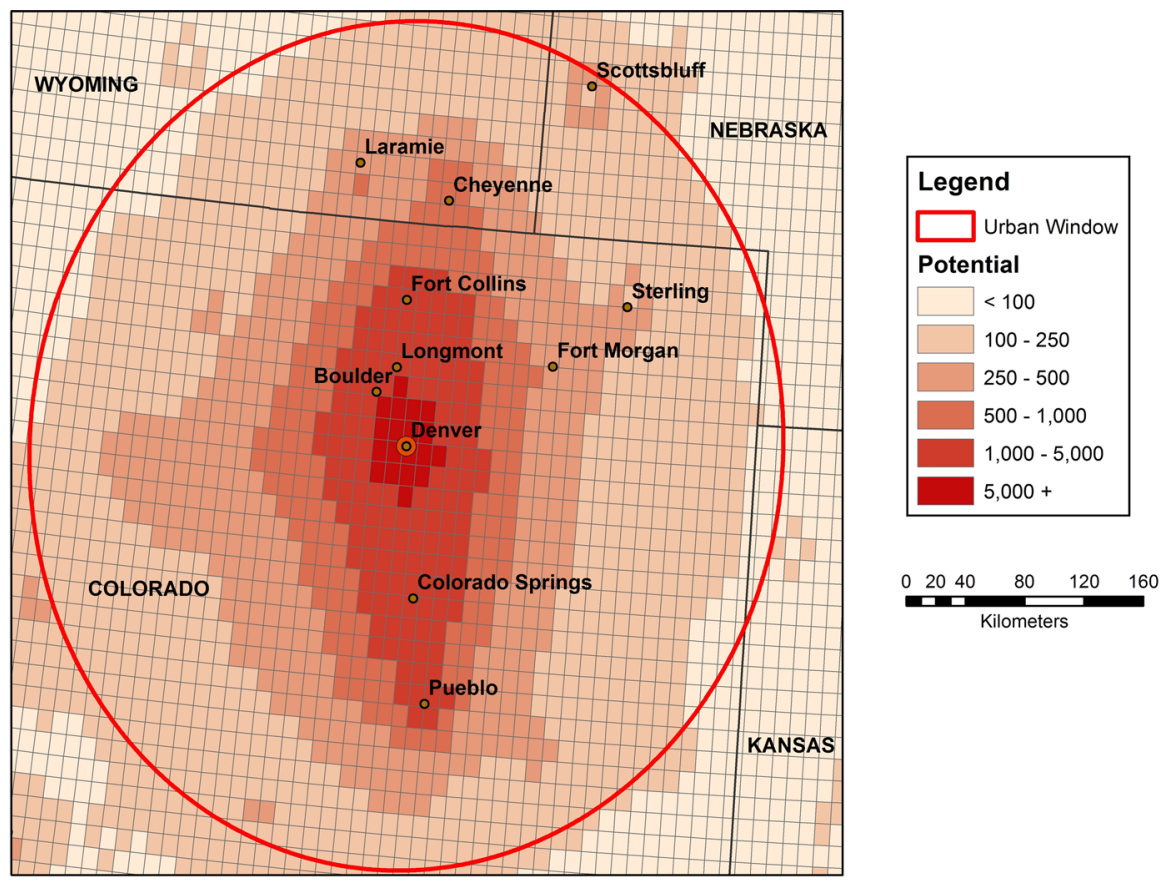

Fig. 3 Denver area population potential surface: urban window, 2000 

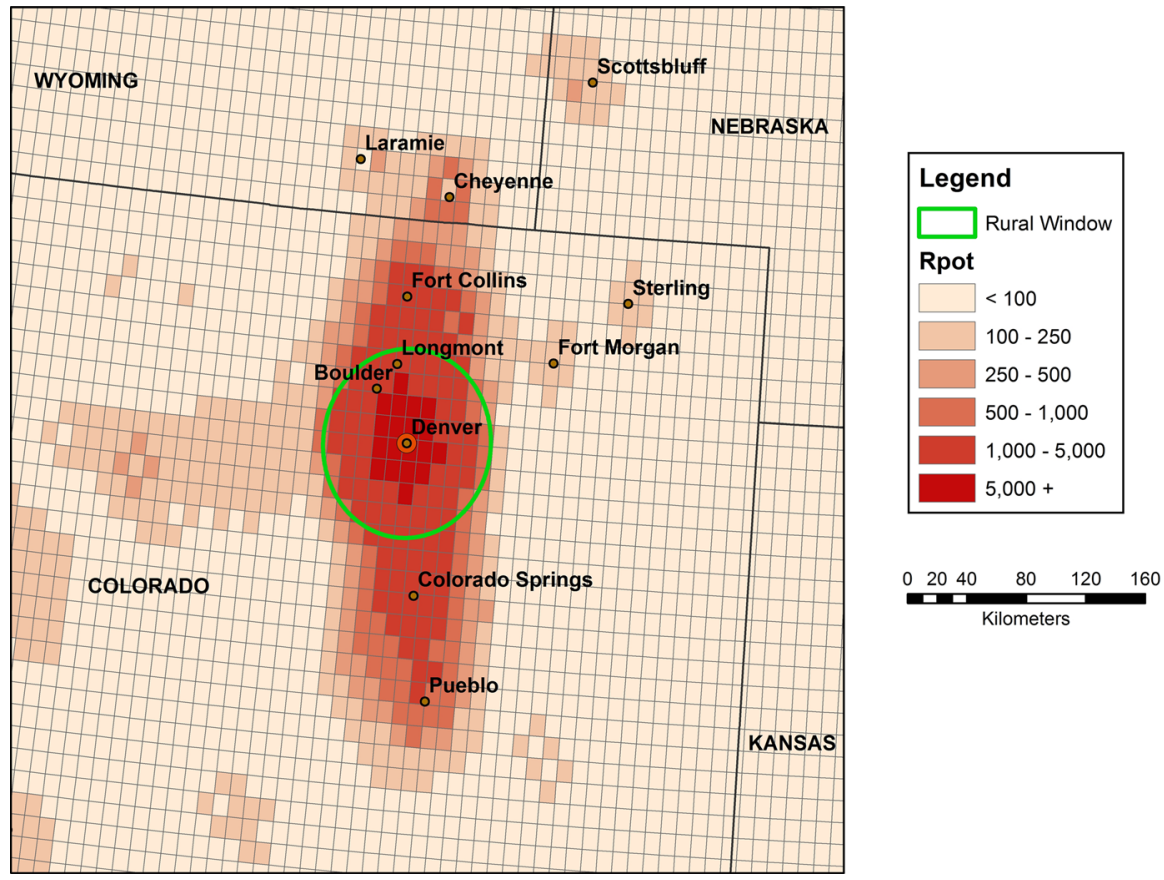

Fig. 4 Denver area population potential surface: rural window, 2000

over multiple time steps, in the absence of a self-potential term, potential then acts as a smoothing agent.

Over long periods the potential model reinforces a dynamic tendency towards homogeneity (Sheppard 1979), in this case a uniform population distribution. Over realistic time periods, however, the practical effects of this trend are projected patterns of sprawling urban growth and, in many cases, the development of urban corridors. Projected density will increase more rapidly in peripheral urban areas than in central urban cores (see Fig. 2a, b); these are spatial patterns of change that have been, and continue to be, commonly observed in urbanizing regions of the world. However, the pattern is not ubiquitous to all regions, nor does it capture regional variation in distance-density patterns. Furthermore, the lack of a selfpotential term prohibits the model from projecting urban concentration.

Figure 5 illustrates the distribution of a one-dimensional population after 100 years assuming a uniform base-year distribution. In this case the population moves towards a slightly more concentrated monocentric pattern. Given the known dynamic tendency of the potential model to move a population towards a homogeneous distribution, this result seems counter-intuitive. A uniform population should, hypothetically, remain uniform over time. The movement away from uniformity in this scenario is not related to any of the three factors discussed above, but is instead due to the effect of the boundary on the calculation of potential. 


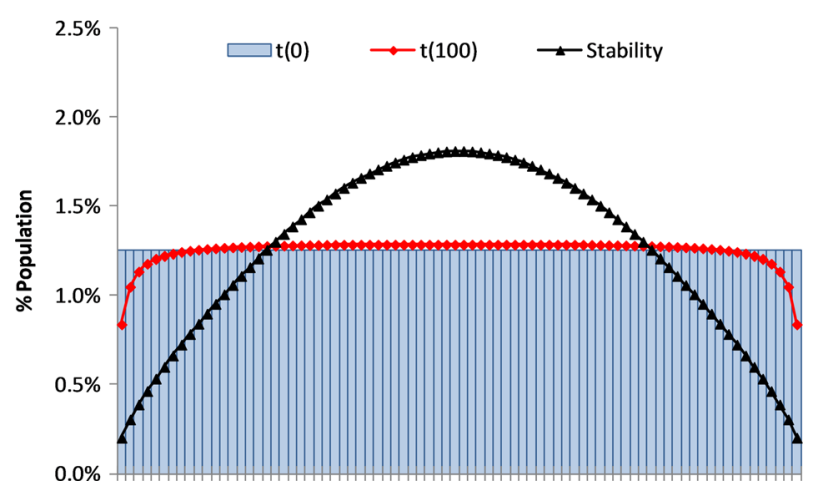

Fig. 5 Population distribution in the base-year, after 100 years, and at stability; uniform distribution, $\mathrm{r}=0.01$

\section{Border effects}

The potential-based downscaling method moves a population towards a spatially stable distribution. Spatial stability is achieved when the relative distribution of population across grid cells no longer changes with the allocation of additional population: the allocation of additional population becomes proportional to the distribution of the existing population. By proxy then, a system reaches stability when the distribution of population is identical to the underlying distribution of potential. ${ }^{8}$ Given the known tendency of the potential model to move a distribution towards homogeneity one would expect a spatially stable distribution to be uniform. However, this is not the case, owing to the impact of the border on the calculation of potential. Consider again Fig. 1a and b, which contain one-dimensional urban populations distributed normally and randomly in the base-year. These populations evolve to an identical distribution at stability. Similarly, given a two-dimensional geography, any base-year population distribution will evolve to the same distribution at stability (Fig. 6a-c).

Evolution to stability, for most populations, occurs over extremely long time periods. Over shorter periods patterns of spatial change projected by the potentialallocation methodology are a function of a population's path to stability. For example, both the polycentric and monocentric populations in Fig. 6a and b will evolve to stability at the distribution illustrated in Fig. 6c. However, the projected distributions of the polycentric and monocentric examples after 100 years will still look quite different from one another. Each population is on a separate path to stability which is governed by the base-year population. With each successive time step the distributions will look more alike, but it will take a very long time for them to really begin to resemble one another. It was found, however, that the form of

\footnotetext{
${ }^{8}$ In an urban/rural system each component of the population evolves towards spatial stability independently, thus stability is achieved when both the urban and rural populations become stable themselves.
} 

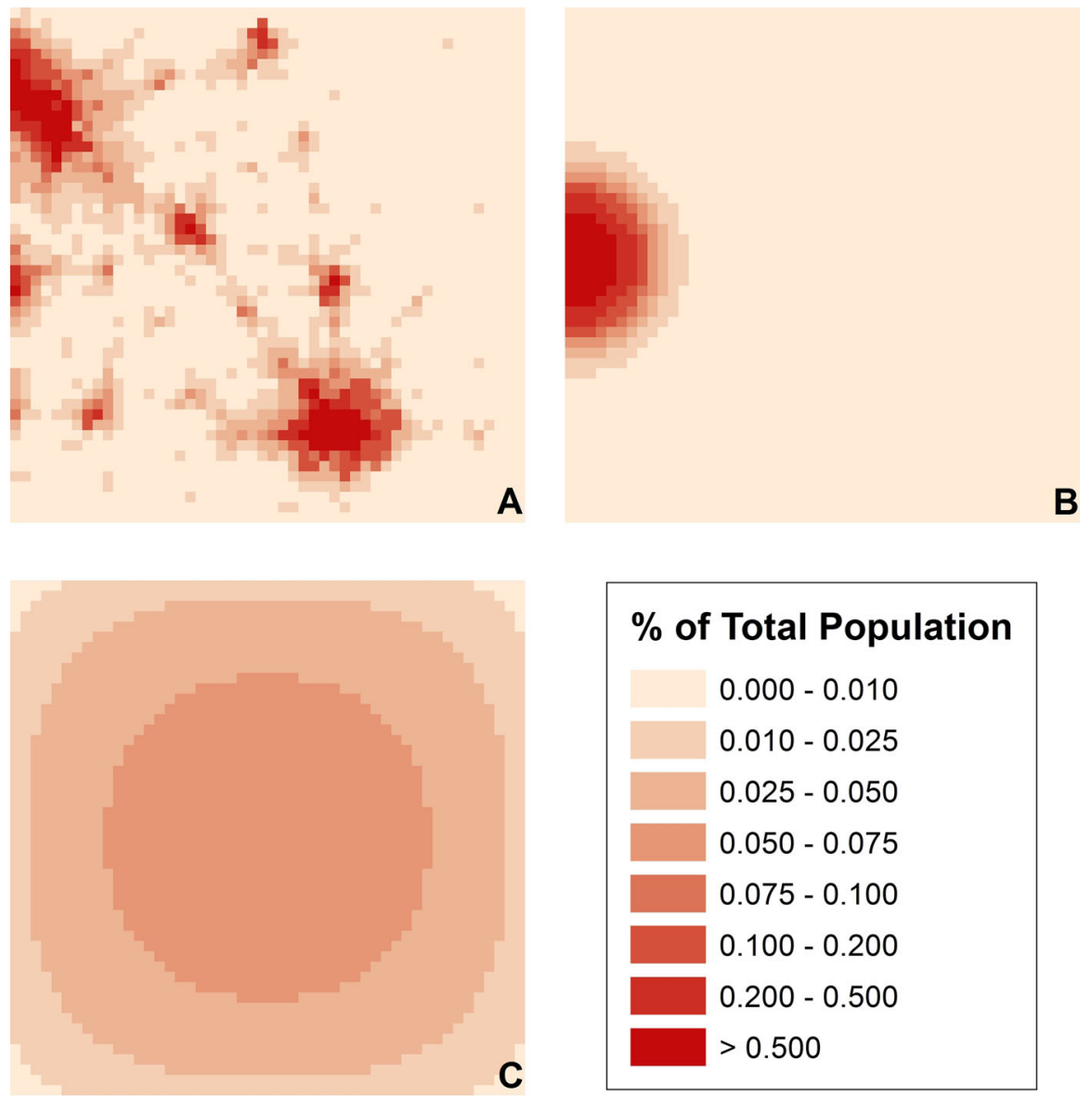

Fig. 6 Two-dimensional hypothetical a polycentric and $\mathbf{b}$ monocentric base-year population distributions and the corresponding (c) distribution at stability

stability for any distribution is a function of the border effect, and in the absence of these effects stability would occur at uniformity.

In a dynamic potential-allocation model the influence of the border on the projected population in any given grid cell $i$ results from two geographic factors: the number of other cells $j$ contributing to potential and the average distance to those cells. The former is referred to as the 'window effect' and the later as the 'positional effect'.

The window effect, illustrated in Fig. 7, is analogous to the boundary problem often noted in point pattern analysis or kernel density estimation (Jones 1993). Consider a diagonal cross-section of a $50 \times 50$ set of urban grid cells (Fig. 7b). The number of other cells $j$ contributing to potential is larger for those cells more centrally located. Because potential is additive, those cells towards the interior of a distribution are likely to exhibit higher potentials than those nearer the boundary. 


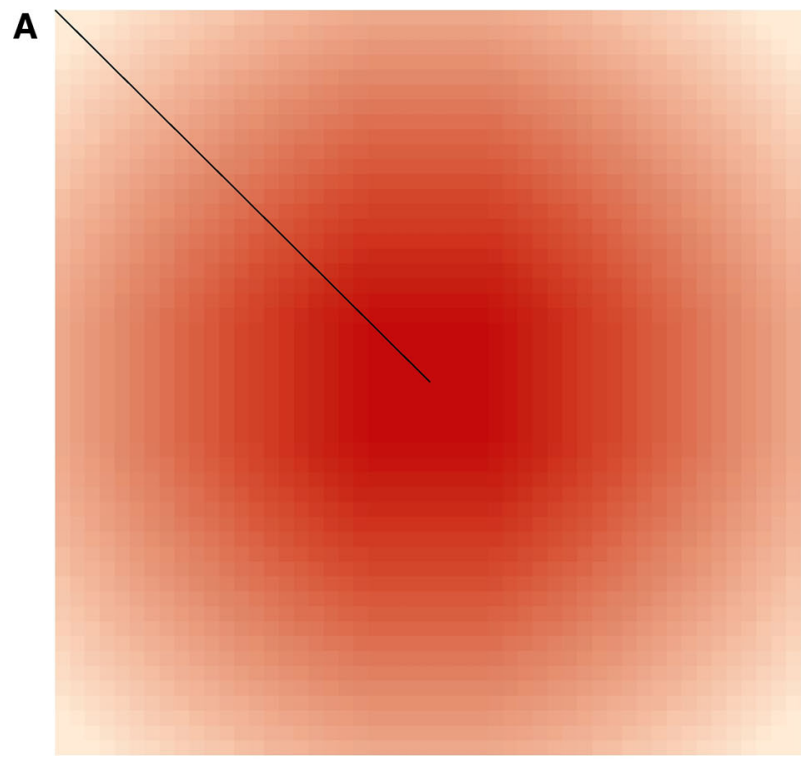

\section{Contributing cells}

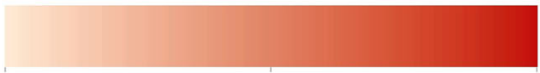

Low: 392

High: 1,481

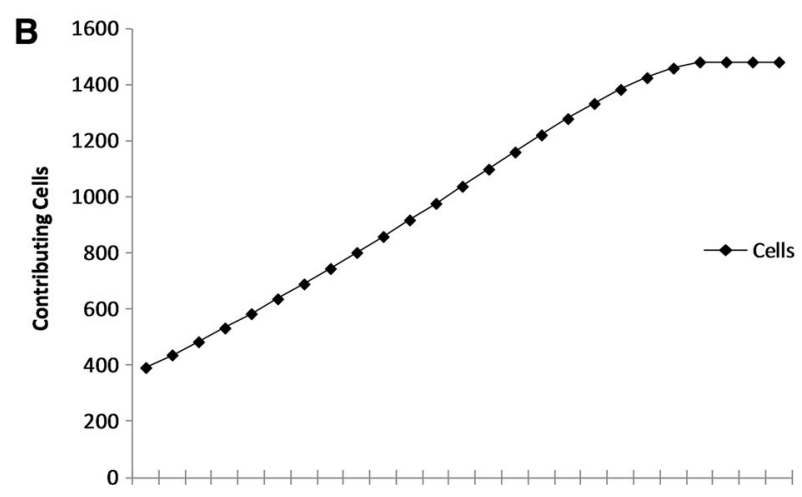

Fig. 7 The window effect in a two-dimensional space and $\mathbf{b}$ along a transect of the distribution

The positional effect results from variation in the proximity of each cell $i$ to those other cells $j$ that contribute to its potential. To assess relative proximity, calculate the average distance for each cell $i$ to all contributing cells $j$. Cells exhibiting the shortest average distance are those in which the highest proportion of contributing cells $j$ are located nearby. Variation in this value results from the potential window extending beyond the boundary, thus reducing the average distance to contributing cells for those cells located nearer to the boundary. From Fig. 8, again considering a 


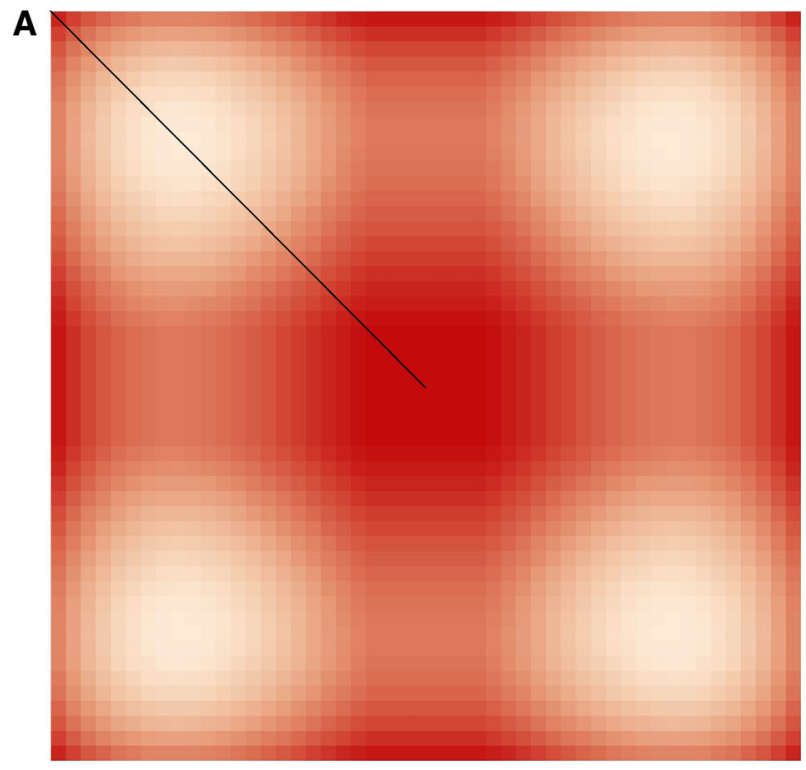

\section{Average distance}

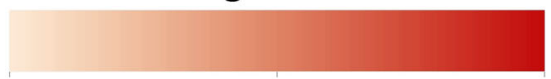

Low: $177 \mathrm{~km}$

High: $203 \mathrm{~km}$

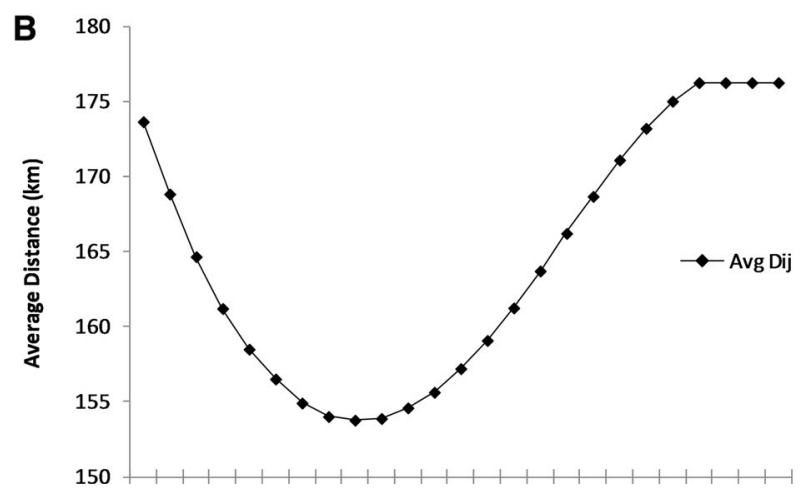

Fig. 8 The positional effect in a two-dimensional space and $\mathbf{b}$ along a transect of the distribution

$50 \times 50$ urban region, note that cells exhibiting the shortest average distances are located inland from the border along the diagonals.

The window and positional effects combine to yield a border effect (Fig. 9a) that varies based on a cell's position relative to both the boundary and other cells in the area. Considering the diagonal cross-section of the $50 \times 50$ urban example (Fig. 9b) it is possible to isolate the separate impact of the window and positional effects by considering the distribution of potential given a uniform population 


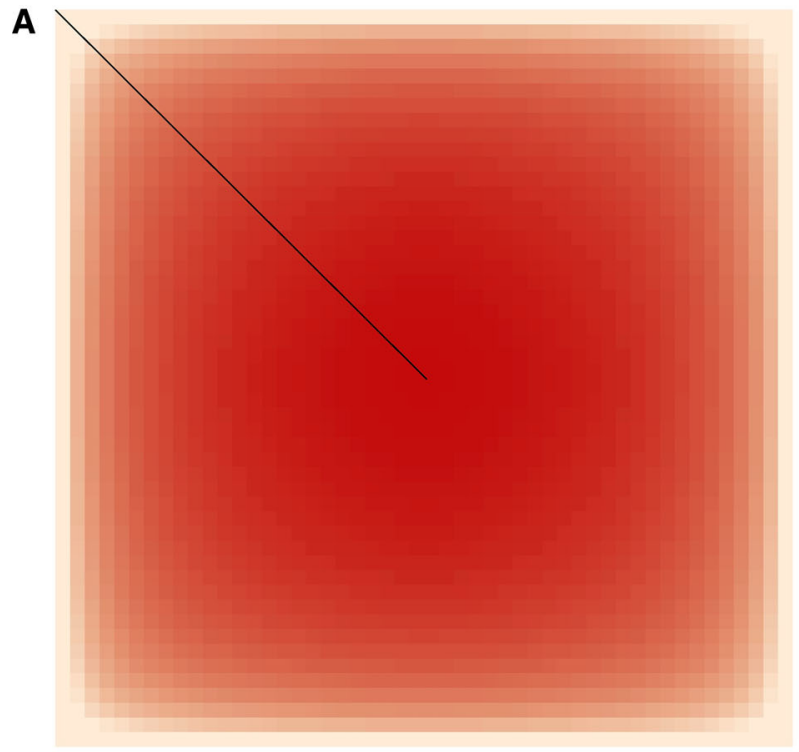

\section{Population potential}
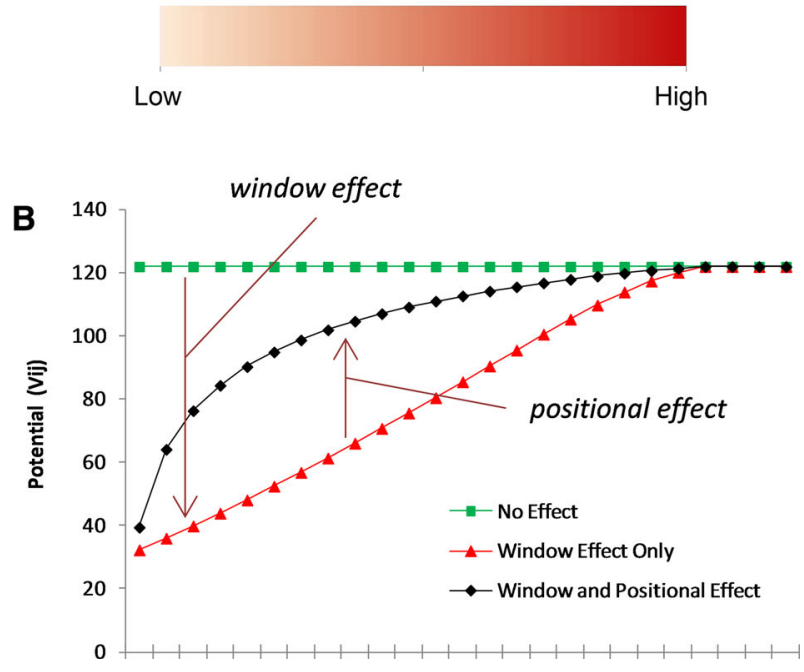

Fig. 9 The border effect in a two-dimensional space and $\mathbf{b}$ disaggregated into the window and positional effects along a transect of the distribution

distribution. In the absence of border effects the distribution of potential would be uniform (squares). Including only the window effect (by assuming that the average contribution of each contributing cell $j$ is the same regardless of position) yields a distribution of potential that declines steadily with movement towards the boundary (triangles). The cell-specific impact of the window effect is therefore the distance between the top and bottom lines. Finally, including the positional effect, by allowing the average contribution of each contributing cell $j$ to vary with position, 
leads to a final distribution of potential that decreases with movement away from the centre, gradually at first but with greater magnitude towards the border (diamonds). The cell-specific impact of the positional effect is the distance between the bottom line and the centre line. The positional effect works against the window effect, and is smallest at the centre of the distribution and along the border.

The potential-allocation procedure moves populations towards spatial stability which, owing to border effects, is a distribution in which density is highest in those cells most removed from the border and lowest in those along the border. Three conclusions are drawn from these results: border effects are a function of the geography of a region (the size and shape of the region which governs the number of cells and the distance matrix); the distribution of a population at stability is also a function of geography, through the impact of the border; and the base-year distribution of population does not influence the border effect; however, projected shorter-term spatial population outcomes are a function of the path from the baseyear distribution to the distribution at stability.

To illustrate the impact of the border in a real-world scenario consider Fig. 10a and $\mathrm{b}$, which contain projected 100-year grid-cell specific population change as a function of distance from the centre of El Paso, Texas for the IIASA A2 scenario. The El Paso metro area is situated on the US-Mexico border which, in this scenario, was treated as an impermeable boundary. Figure 10a contains the population change-gradient for all cells within $50 \mathrm{~km}$ of the city centre, differentiating between those cells that are on the border and inland form the border. Note that all border cells fall below the change-gradient. Furthermore, border and inland cells exhibit distinctly different population change gradients, indicating that projected population change will vary in cells with similar populations situated a similar distance from the city centre as a function of position relative to the border (Fig. 10b).

The hypothetical examples considered above included only urban population. The effect of the border is easily identifiable and exhibited in such scenarios. However, within the context of the IIASA-type potential allocation procedure, the effect of the boundary is more complicated when urban and rural populations are considered simultaneously. Within urban and rural regions the effect of the boundary operates as described above, generally orienting the projected urban population towards the most central urban cells and the rural population to the most central rural cells. Despite the separate allocation of projected change, urban and rural populations do influence one another through the calculation of potential. Thus, the location of the urban/rural border affects spatial population outcomes. Because the more problematic features related to the location of the urban/rural border result from the classification/allocation algorithm they are discussed in the next section.

Urban/rural windows, classification, and population allocation

The potential-allocation procedure often leads to unrealistic spatial patterns along the urban/rural border. Furthermore, the method has specific implications regarding the spatial allocation of urban-to-rural migrants and the corresponding patterns of urbanization and the growth of suburbs. Figure 11a and b contains 100-year spatial 

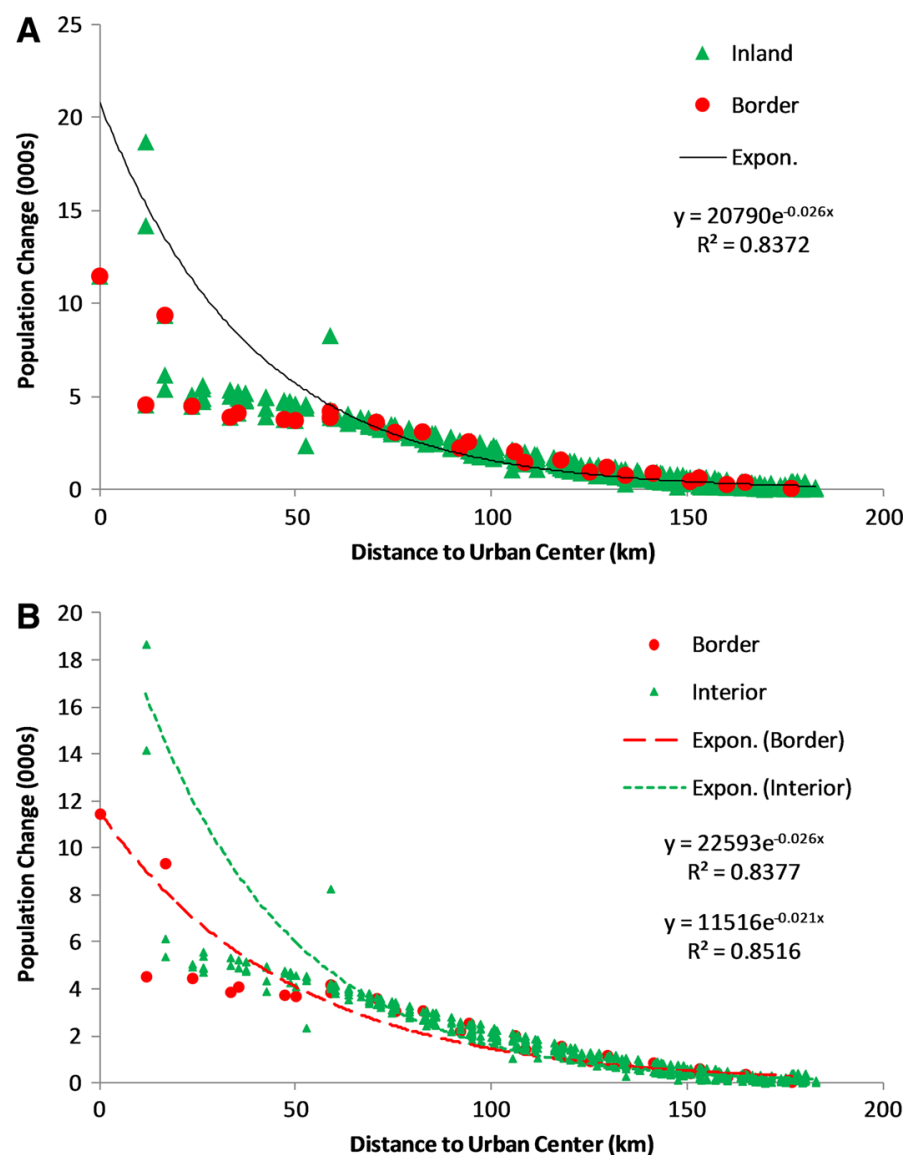

Fig. 10 Projected population change gradients for the metro El Paso area; a all cells and b border and inland cells, IIASA A2 scenario (1990-2100)

outcomes for one-dimensional urban/rural populations distributed (A) normally and (B) randomly in the base-year. In both cases the urban growth rate is assumed to exceed the rural growth rate. Two distinct features are noteworthy in the outcome: a centrally located urban peak density, and a dramatic decline in density at the urban/ rural border. The former is a result of the characteristic movement of the population towards a peak density in the most interior cells, brought on by the border effect, but it is occurring within urban and rural regions independently. Second, there is a noticeable drop in population density along the urban/rural boundary. The later pattern is directly related to the classification of cells as urban or rural, and the separate allocation of urban and rural population change. The procedure allocates projected urban and rural population change only to cells with shared classification, that is, urban population to urban cells. If, as is often the case, urban growth exceeds rural growth, more population is allocated into cells defined as urban than to cells classified as rural. Furthermore, because urban regions tend to encompass smaller 

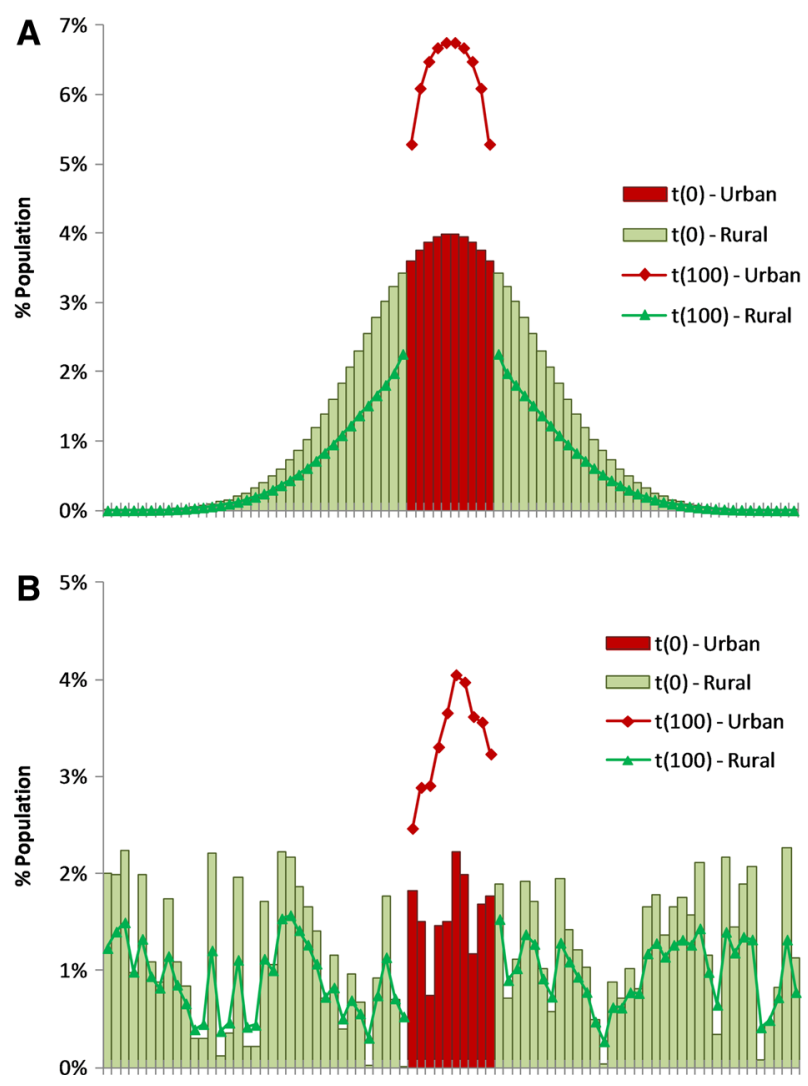

Fig. 11 Population distribution in the base-year and after 100 years; urban/rural a normal and $\mathbf{b}$ random scenarios, $\mathrm{r}(\mathrm{u})=0.015, \mathrm{r}(\mathrm{r})=0.005$

geographic areas than rural regions, urban population growth is allocated across a smaller subset of cells than rural growth. The result is the projection of a density 'cliff' along the urban/rural border illustrated in Fig. 11b.

Urban-to-rural migration is typically a component of the aggregate projections of urban and rural change that are fed into the model. Thus, people who are reclassified as urban owing to a move are allocated into grid cells that are defined as urban. Theoretically cells can be reclassified as urban once population density reaches a certain threshold, allowing for urban expansion and suburbanization. However, if population density is the mechanism through which cells are reclassified at the beginning of each time step, given reasonable rates of urban and rural change, rural cells generally do not reach the density thresholds necessary for reclassification, even over longer time periods. More often than not, rural population growth is minimal in comparison to urban growth, and in many countries the rural population is expected to decline. The practical result is a spatial projection in which horizontal urban growth occurs only across those cells defined as urban in the base year. However, sprawling growth within those cells will occur quickly (see 'Limited patterns of spatial change' section). In the IIASA scenarios this was evident in the 
rapid development of urban corridors and sprawling growth around existing cities, but occurring in cells that contained urban population in the base year. Thus, patterns of urbanization and suburban growth are highly dependent on the base year classification of urban/rural population. Within cells defined as urban, particularly those more compact cities encompassing only a few urban cells, rapid vertical growth occurs when urbanization growth rates are high. The broad implication is that those cells defined as urban in the base year will grow quickly relative to those defined as rural, but the urban/rural boundary will not move.

These conclusions were tested and verified using multiple variations of the hypothetical scenarios presented here (see Jones 2012) and in a test against historical census data for the United States (gridded at 7.5') in which the model was applied to the 1,950 spatial data in an attempt to replicate the 2000 distribution. Grid-cell marginal average percentage error (MAPE) for the urban population was $41.9 \%$, compared to $16.6 \%$ for the rural population. The cause of the wide gap in error is twofold. First, because the urban population grew far more the rural population over the 50-year period (129 vs. $8 \%$ ) there was more exposure to allocation error. Second, because reclassification of cells from rural to urban is unlikely within the context of the model, the projected 2000 urban population was overly concentrated in areas that had experienced significant sprawl during the period (e.g., Atlanta, Houston). MAPE for the total population was just over $35 \%$.

\section{Misallocation of population loss}

To this point the examples presented have considered populations experiencing growth. Population decline, however, is a commonly observed phenomenon, particularly in rural areas. The potential-allocation approach misallocates population loss because it is allocated proportionally according to potential in the same manner as population gain, thus leading to more population loss in those cells deemed more attractive.

The misallocation of population loss within the context of population potential is more likely to be problematic in remote rural areas, where population loss is common. Again, IIASA did not apply their potential-allocation method to rural populations, but this work did explore the capacity of the potential-allocation procedure to model both urban and rural population dynamics. During periods of rural decline, very common throughout the world, population loss is disproportionally allocated to those rural cells with the highest potential. In the highlyurbanized developed world these cells almost always fall on the urban/rural border; thus rural population loss would be concentrated in areas nearest to urban centres. This would be the equivalent of projecting suburban population loss that exceeds relative population loss in the remote hinterlands, an unlikely spatial pattern.

Allocation into areas not suited for development

The final characteristic of the model is a noticeable tendency to allocate projected future population into places that are either unsuitable for human habitation, or are protected from development. For example, consider Fig. 12, which contains the observed 1,990 and projected 2,100 gridded populations (IIASA A2 scenario) for 

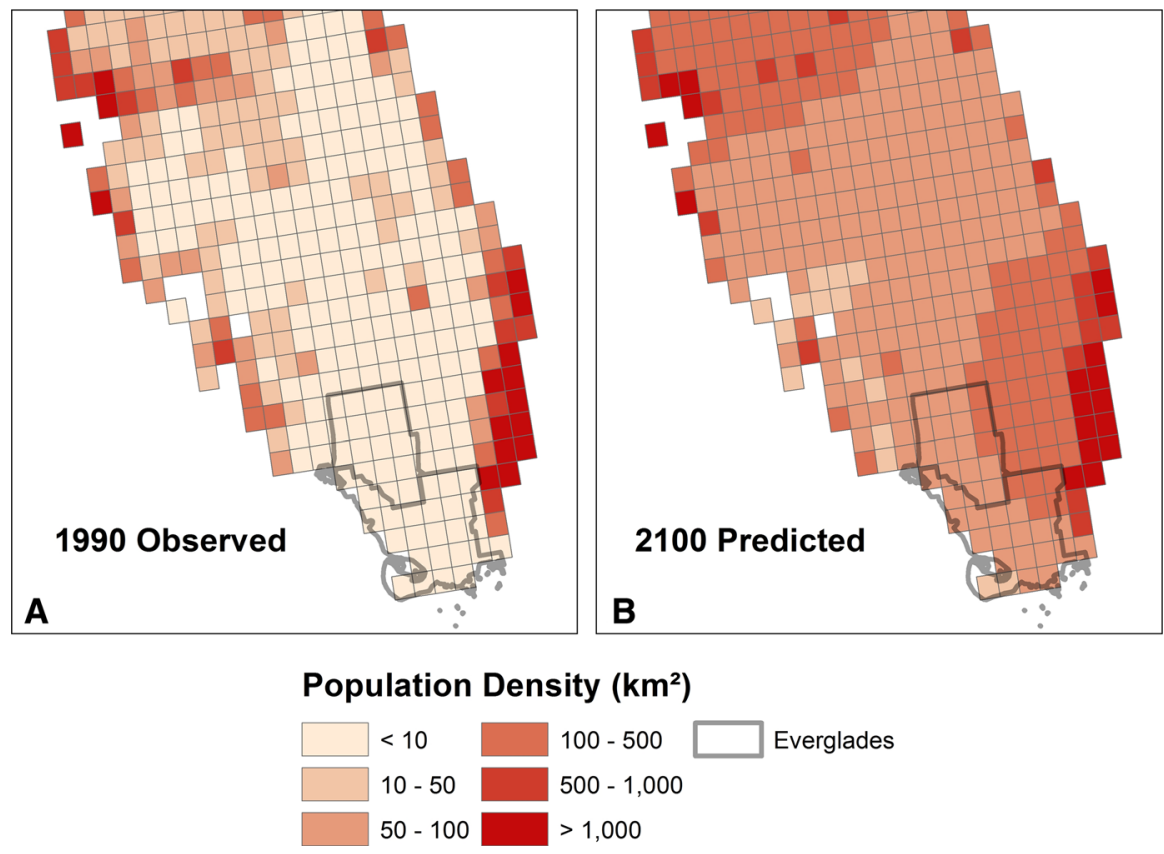

Fig. 12 Observed (1990) and predicted (2100) gridded population in South Florida, IIASA A2 scenario

South Florida. In the case of the former a large portion of the southwestern tip of the Florida Peninsula is part of Everglades National Park. This area is both protected from and not suitable for human development. Of course one could envisage a scenario in which the swampland in South Florida is drained and developed, but such a process would be extremely expensive, and is very unlikely given its status as a National Park. Thus it would be appropriate to avoid allocating population into the grid cells that encompass this area.

\section{Conclusions and recommendations}

The IIASA potential-allocation method is an improvement upon previously existing methods of constructing large-scale spatial population projections in that it does not use a simple scaling technique or trend extrapolation. Instead the method makes use of a common tool in spatial allocation and accessibility modelling; the gravity-based population potential model. The flexibility, simplicity, and wide application of this model in the geographic literature are attractive features of the method. Furthermore, the ability of the model to replicate a few widely observed patterns of spatial change such as urban sprawl represents a marked improvement over previous methods. The dynamic application of a gravity-based spatial allocation model appears to hold promise as a method for constructing large-scale spatial population projections. However, despite significant improvement over many existing models, 
the potential-allocation procedure is subject to several shortcomings that merit consideration.

Because of a fixed distance-decay function, a relatively large bandwidth, and the lack of a self-potential term, the IIASA form of the potential-allocation model can only produce limited patterns of spatial change, which in most cases will be one of dispersion. The rigid application of a fixed distance-response function implies a globally ubiquitous distance response pattern. In reality these patterns vary across regions. It may prove advantageous to consider a distance-decay function that can be parameterized and calibrated to reflect local patterns of spatial change relative to distance. Furthermore, to expand the capacity of the model to produce alternative patterns of spatial change it would beneficial to either add a self-potential term to the existing metric, or consider an alternative form of the distance-decay such as the negative exponential function.

The effects of boundaries on spatially explicit metrics are well documented in the geographic literature. Significant similarities exist between the population potential model and, for example, kernel density estimation. In the case of the latter there is currently a significant literature concerning the impact of the boundary, and removing this impact. There is no reason to believe that a border, physical or political, naturally repels population, so removing boundary effects from the existing model would improve spatial projections.

The classification of cells as urban or rural, the allocation algorithm, the use of separate urban and rural potential windows, and by proxy the location of the urban/ rural border all have the capacity to significantly affect spatial population outcomes. The IIASA scenarios were among the first to explicitly consider the spatial distribution of urban and rural populations, and in that context were an improvement over existing scenarios. However, the treatment of these populations can lead to problematic spatial patterns along the urban/rural boundary, and confound estimates of urban-to-rural migration. In the future it may be necessary to reconsider how these populations are treated; for example, it may prove useful to define population as urban or rural, but not grid cells, which would allow for the allocation of both components into any one cell and may eliminate reclassification issues. Furthermore, to eliminate problems related to the urban and rural windows, it may be useful to consider using a single potential window.

During periods of population decline the potential-allocation model allocates proportionally more population loss into cells with higher potential. To alleviate this problem it may prove useful to consider, during periods of population decline, allocation according to the inverse of potential. This change would lead to the allocation of proportionally larger population losses in cells with lower potential which, if potential is interpreted as indicative of attractiveness, fits with historical patterns of rural population decline. Similar misallocation occurs when populations are projected to encroach on areas not suitable for human development and habitation, a problem that could be alleviated by applying a geospatial mask. For example, using spatial data for surface water, slope and elevation, and protected land, one could determine the portion of each grid cell suitable for habitation. These data could then be used to weight cell-specific potential, thus limiting the allocation into areas such as the Florida Everglades, which exist in close proximity to large 
metropolitan areas, and thus would exhibit high potential, but are largely uninhabitable. Finally, it merits noting that the potential-allocation downscaling method does not directly account for the demographic forces that drive population change. Instead fertility, mortality, and migration are components of the exogenously generated aggregate projections of urban and rural change that are fed into the downscaling procedure. Furthermore, the degree to which internal migration is considered is dependent on the number of subnational areal units for which aggregate projections are produced and then downscaled. ${ }^{9}$ Fertility, mortality, and migration have been shown to exhibit characteristics that vary over space (Balk et al. 2004; Guilmoto and Rajan 2004). In the future it may be useful to consider methods for using these factors to further improve spatial projections.

The potential-allocation procedure holds considerable promise as a method for constructing global-scale spatial population projections. The increasing availability of globally consistent geospatial data and modelling capabilities of GIS applications will improve the ability of such models to capture and replicate complex processes, often at subregional levels. Such models are useful in the large-scale modelling of global change processes and are crucial to the study of human vulnerability to climate-related hazards. Additionally, a diverse community of potential users outside the global-change community will benefit from improved spatial projections including, for example, municipal planners, as well as various business, real estate, and insurance interests. Therefore, continued work towards the production of improved spatial population projections is merited.

Open Access This article is distributed under the terms of the Creative Commons Attribution License which permits any use, distribution, and reproduction in any medium, provided the original author(s) and the source are credited.

\section{References}

Arnell, N. W. (2004). Climate change and global water resources: SRES emissions and socio-economic scenarios. Global Environmental Change, 14(1), 31-52.

Asadoorian, M. (2005). Simulating the spatial distribution of population and emissions to 2100. Environmental and Resource Economics, 39(3),199-221.

Bailey, T. C., \& Gatrell, A. C. (1995). Interactive spatial data analysis. Harlow: Longman.

Balk, D. L., Deichmann, U., Yetman, G., Pozzi, F., Hay, S. I., \& Nelson, A. (2006). Determining global population distribution: Methods, applications and data. Advances in Parasitology, 62, 119-156.

Balk, D., Montgomery, M. R., McGranahan, G., \& Todd, M. (2009). Understanding the impacts of climate change: Linking satellite and other spatial data with population data. In J. M. Guzman, G. Martine, G. McGranahan, D. Schensul, \& C. Tacoli (Eds.), Population dynamics and climate change (pp. 206-217). London: IIED/UNFPA.

Balk, D. L., Pullum, T., Storeygard, A., Greenwell, F., \& Neuman, M. (2004). A spatial analysis of childhood mortality in West Africa. Population Space and Place, 10(3), 175-216.

Braimoh, A. K., \& Onishi, T. (2007). Spatial determinants of urban land use change in Lagos Nigeria. Land Use Policy, 24(2), 502-515.

\footnotetext{
9 For example, a national-level aggregate projection includes no information about internal migration, whereas state-level projections would, theoretically, include information about interstate migration trends. Thus, downscaling projections at the state level would lead to a spatial distribution that does account for state-to-state migration.
} 
Center for International Earth Science Information Network (CIESIN)/Columbia University, International Food Policy Research Institute, The World Bank, and Centro Internacional de Agricultura Tropical. (2011). Global rural-urban mapping project, Version 1 (GRUMPv1): Population density grid. Palisades, NY: NASA Socioeconomic Data and Applications Center.

Clark, W. A. V., \& Davies, S. D. (2002). Changing jobs and changing houses: Mobility outcomes of employment transitions. Journal of Regional Science, 39(4), 653-673.

Craig, J. (1987). Population potential and some related measures. Area, 19(2), 141-146.

Deichmann, U., \& Eklundh, L. (1991). Global digital datasets for land degradation studies: A GIS approach (p. 4). Nairobi: United Nations Environment Programme, Global Resource Information Database, Case Study No. 4

Dobson, J. E., Bright, E. A., Coleman, P. R., Durfee, R. C., \& Worley, B. A. (2000). LandScan: A global population database for estimating populations at risk. Photogrammetric Engineering and Remote Sensing, 66, 849-857.

Frost, M. E., \& Spence, N. A. (1995). The rediscovery of accessibility and economic potential: The critical issue of self-potential. Environment and Planning A, 27(11), 1833-1848.

Geertman, S. C. M., \& Ritsema Van Eck, J. R. (1995). GIS and models of accessibility potential: An application in planning. International Journal of Geographical Information Systems, 9(1), 67-80.

Grübler, A., O’Neill, B., Riahi, K., et al. (2007). Regional, national, and spatially explicit scenarios of demographic and economic change based on SRES. Technological Forecasting and Social Change, 74(7), 980-1029.

Guilmoto, C. Z., \& Rajan, S. I. (2004). Spatial patterns of fertility transition in Indian districts. Population and Development Review, 27(4), 713-738.

Gustafson, P. (2001). Roots and routes: Exploring the relationship between place attachment and mobility. Environment and Behavior, 33(5), 667-686.

Hachadoorian, L., Gaffin, S. R., \& Engelman, R. (2011). Projecting a gridded population of the world using ratio methods of trend extrapolation. In R. P. Cincotta \& L. J. Gorenflo (Eds.), Human population (pp. 13-25). Berlin: Springer.

Haugen, K., Holm, E., Stromgren, M., Vilhelmson, B., \& Westin, K. (2012). Proximity, accessibility and choice: A matter of taste or condition? Papers in Regional Science, 9(1), 65-85.

Haynes, R., Lovett, A., \& Sunnenberg, G. (2003). Potential accessibility, travel time, and consumer choice: Geographical variations in general medical practice registrations in Eastern England. Environment and Planning A, 35(10), 1733-1750.

Ingram, D. R. (1970). The concept of accessibility: A search for an operational form. Regional Studies, 5(2), 101-107.

Jones, B. (2012). Assessment of the potential-allocation downscaling methodology for constructing spatial population projections. Technical note, national center for atmospheric research. http://nldr. library.ucar.edu/repository/collections/TECH-NOTE-000-000-000-852.

Jones, M. C. (1993). Simple boundary correction for kernel density estimation. Statistics and Computing, $3(3), 135-146$.

Kim, T.-K., Horner, M. W., \& Marans, R. W. (2005). Life cycle and environmental factors in selecting residential and job locations. Housing Studies, 20(3), 457-473.

Middleton, N., Gunnell, D., Frankel, S., Whitley, E., \& Dorling, D. (2003). Urban-rural differences in suicide trends in young adults: England and Wales, 1981-1998. Social Science and Medicine, 57(7), 1183-1194.

Nakicenovic, N., Intergovernmental Panel on Climate Change, World Meteorological Organization, \& United Nations Environment Programme. (2000). Special report on emissions scenarios: A special report of working group III of the intergovernmental panel on climate change. New York: Cambridge University Press.

Nam, K.M., \& Reilly, J.M. (2012). City size distribution as a function of socioeconomic conditions: An eclectic approach to downscaling global population. Urban Studies. doi:10.1177/00420980 12448943.

O'Kelly, M. E., \& Horner, M. W. (2003). Aggregate accessibility to population at the county level: U.S. 1940-2000. Journal of Geographical Systems, 5(1), 5-23.

Polyzos, S., \& Arambatzis, G. (2006). Labour productivity of agricultural sector in Greece: Determinant factors and interregional differences analysis. Mediterranean Journal of Economics Agriculture and Environment, 5(1), 58-64.

Pooler, J. (1987). Measuring geographical accessibility: A review of current approaches and problems in the use of population potential. Geoforum, 18(3), 269-289. 
Raupach, M. R., Rayner, P. J., \& Page, M. (2010). Regional variations in spatial structure of nightlights, population density and fossil fuel $\mathrm{CO}_{2}$ emissions. Energy Policy, 38(9), 4756-4764.

Riahi, K., Grübler, A., \& Nakicenovic, N. (2007). Scenarios of long-term socio-economic and environmental development under climate stabilization. Technological Forecasting and Social Change, 74(7), 887-935.

Rich, D. C. (1980). Potential models in human geography. Concepts and techniques in modern geography 26. Norwich: University of East Anglia.

Rockström, J., Falkenmark, M., Karlberg, L., Hoff, H., Rost, S., Gerten, D. (2009). Future water availability for global food production: The potential of green water for increasing resilience to global change. Water Resources Research. doi:10.1029/2007WR006767.

Rosero-Bixby, L. (2004). Spatial access to health care in Costa Rica and its equity: A GIS-based study. Social Science and Medicine, 58(7), 1271-1284.

Sheppard, E. (1979). Geographic potentials. Annals of the Association of American Geographers, 69(3), $438-447$.

Shuttlesworth, I., \& Gould, M. (2010). Distance between home and work: A multilevel analysis of individual workers, neighbourhoods, and employment sites in Northern Ireland. Environment and Planning A, 42(5), 1221-1238.

Small, C. (2004). Global population distribution and urban land use in geophysical parameter space. Earth Interactions, 8(8), 1-18.

Stewart, J. Q. (1942). A measure of the influence of population at a distance. Sociometry, 5(1), 63-71.

Stewart, J. Q., \& Warntz, W. (1958). Physics of population distribution. Journal of Regional Science, 1(1), 99-123.

Sweitzer, J., \& Langaas, S. (1995). Modelling population density in the Baltic Sea States using the Digital Chart of the World and other small scale data sets. In V. Gudelis, R. Povilanskas, A. Roepstorff (eds), Coastal conservation and management in the Baltic region, proceedings of the EUCC-WWF conference (pp. 257-267). 2-8 May 1994, Riga-Klaipeda-Kaliningrad.

van Vuuren, D. P., Edmonds, J., Kainuma, M., et al. (2011). The representative concentration pathways: An overview. Climactic Change, 109, 5-31.

van Vuuren, D. P., Lucas, P. L., \& Hilderink, H. (2007). Downscaling drivers of global environmental change: Enabling use of global SRES scenarios at the national and grid levels. Global Environmental Change, 17(1), 114-130.

Verburg, P. H., van Eck, J. R. R., de Nijs, T. C. M., Dijst, J., \& Schot, P. (2004). Determinants of land-use change patterns in the Netherlands. Environment and Planning B, 31(1), 125-150.

Vickerman, R., Spiekermann, K., \& Wegener, M. (2010). Accessibility and economic development in Europe. Regional Studies, 33(1), 1-15.

Wang, F., \& Guldmann, J. (1996). Simulating urban population density with a gravity-based model. Socio Economic Planning Sciences, 30(4), 245-256.

Warntz, W., \& Wolff, P. (1971). Breakthroughs in geography. New York: Plume.

Weber, J., \& Sultana, S. (2012). Why do so few minority people visit national parks? Visitation and the accessibility of 'America's best idea'. Annals of the Association of American Geographers. doi:10.1080/00045608.2012.689240.

Weibull, J. W. (1976). An axiomatic approach to the measurement of accessibility. Regional Science and Urban Economics, 6(4), 357-379.

Yeates, M. (1974). An introduction to quantitative analysis in human geography. New York: McGrawHill. 